\title{
SISTEM KONTROL PELANGGARAN MEROKOK SANTRI DI PPNJ MENGGUNAKAN MIKROKONTROLLER DAN INTERNET OF THING (IOT)
}

\author{
Mohammad Edi Prastiono ${ }^{1)}$, Tijaniyah ${ }^{2)}$, Hilman Saraviyan Iskawanto ${ }^{3)}$ \\ Program Studi Teknik Elektro Fakultas Teknik Universitas Nurul Jadid \\ Karanganyar Paiton Probolinggo \\ Email:edypras@gmail.com ${ }^{1}$, tijaniyah@gmail.com $^{2)}$, hilman@gmail.com $^{3)}$
}

Pondok Pesantren Nurul Jadid (PPNJ) merupakan sebuah lembaga pendidikan pondok pesantren yang berlokasi di Desa Karang Anyar Kecamatan Paiton Kabupaten Probolinggo. Pondok Pesantren Nurul Jadid dapat menghasilkan lulusan yang berkualitas baik secara intelektual. Seorang santri dapat mempelajari ilmu agama maupun ilmu pendidikan lainnya bertujuan untuk mengajarkan santri tersebut kedisiplinan. Santri diwajibkan mentaati peraturan yang ditetapkan didalam pesantren tersebut. Salah satunya peraturan dilarang merokok (bagi santri putra) karena asap rokok sangat berbahaya bagi kesehatan. Apabila ada santri yang melanggar akan dikenakan sanksi sesuai dengan pelangaran yang dilakukan. Selama ini pelanggaran merokok jarang diketahui oleh pengurus pesantren sehingga santri tidak dikenakan sanksi atas pelanggaran yang dibuat karena ketidak tahuan pengurus pesantren. Untuk mengatasi masalah di atas, maka dibuatlah alat yang mampu membantu para pengurus pesantren dengan memanfaatkan teknologi Internet of Things (IOT).

Alat ini dirancang dapat membantu pengurus agar dapat menindak lanjuti santri yang melanggar, pengurus hanya mendapatkan pesan telegram. Alat ini menggunakan nodemcu esp8266 sebagai mikrokontroler yang dilengkapi dengan modul wifi. Dan sensor mq2 untuk mendeteksi asap rokok di kamar santri putra. Jika sensor mendeteksi asap rokok maka nodemcu esp 8266 akan mengirim pesan ke telegram. Jika sensor mq 2 tidak mendeteksi asap rokok maka nodemcu esp 8266 tidak mengirim pesan telegram.

Kata kunci : sensor mq 2, mikrokontroller, Internet of thing

\section{Pendahuluan}

\subsection{Latar Belakang}

Pondok Pesantren Nurul Jadid (PPNJ) merupakan sebuah lembaga pendidikan pondok pesantren yang berlokasi di Desa Karang Anyar Kecamatan Paiton Kabupaten Probolinggo. Pondok Pesantren Nurul Jadid dapat menghasilkan lulusan yang berkualitas baik secara intelektual.Seorang santri dapat mempelajari ilmu agama maupun ilmu pendidikan lainnya bertujuan untuk mengajarkan santri tersebut kedisiplinan.

Berbagai macam aturan yang di buat oleh pengurus pesantren atau pun kyai agar santri bisa menjalankan kewajibannya dalam mencari ilmu. Santri diwajibkan mentaati peraturan yang ditetapkan didalam pesantren tersebut. Salah satunya peraturan dilarang merokok (bagi santri putra) karena asap rokok sangat berbahaya bagi kesehatan. Apabila ada santri yang melanggar akan dikenakan sanksi sesuai dengan pelangaran yang dilakukan. Selama ini pelanggaran merokok jarang diketahui oleh pengurus pesantren sehingga santri tidak dikenakan sanksi atas pelanggaran yang dibuat karena ketidak tahuan pengurus pesantren. Untuk mengatasi masalah di atas, maka dibuatlah alat yang mampu membantu para pengurus pesantren dengan memanfaatkan teknologi Internet of Things (IOT).

Alat ini dirancang dapat membantu pengurus agar dapat menindak lanjuti santri yang melanggar, pengurus hanya mendapatkan pesan telegram. Apabila seorang santri yang melanggar peraturan pesantren (merokok), dengan bantuan Internet of Things (IOT). Alat ini menggunakan nodemcu esp8266 sebagai mikrokontroler yang dilengkapi dengan modul 
wifi. Dan sensor mq2 untuk mendeteksi asap rokok di kamar santri putra.

\subsection{Rumusan Masalah}

1. Bagaimana membuat alat sistem kontrol pelanggaran merokok santri di pondok pesantren nurul jadid.

2. Bagaimana menggabungkan alat dengan akun telegram.

\subsection{Tujuan Penelitian}

1. Merancang dan membuat suatu alat yang dapat mengendalikan asap rokok dalam ruang tertutup.

2. Memudahkan pengurus pesantren dalam mengetahui santri yang melanggar merokok.

3. Agar santri yang melanggar cepat ditangani oleh pengurus pesantren.

\subsection{Manfaat Penelitian}

\section{Bagi Mahasiswa}

Adapun manfaat penelitian ini bagi mahasiswa antara lain adalah Meningkatkan pengetahuan dan kemampuan peneliti dalam pembuatan sistem kontrol pelanggaran merokok santri di Pondok Pesantren Nurul Jadid menggunakan mikrokontroler dan Internet of Things (IoT).

\section{Bagi Pengurus Pondok Pesatren}

Adapun manfaat penelitian ini bagi pengurus pondok pesantren antara lain adalah Dapat membantu pengurus pondok pesantren dalam monitoring pelanggaran merokok bagi santri.

3. Bagi Program Studi Teknik Elektro Universitas Nurul Jadid

Adapun manfaat penelitian ini bagi proram studi teknik elektro universitas nurul jadid antara lain adalah dapat dijadikan pembelajaran bagi teknik elektro dalam membuat alat sistem kontrol pelanggaran merokok santri di Pondok Pesantren Nurul Jadid menggunakan mikrokontroler dan Internet of Things (IoT).

\subsection{Batasan Masalah}

1. Sensor mq2 hanya diletakkan di kamar santri.

2. Penerima pesan telegram hanya pengurus keamanan wilayah putra.

3. Mikrokontroller yang digunakan NodeMcu ESP8266.

4. Penelitian ini di Kamar Santri Putra Pondok Pesantren Nurul Jadid.

Sensor yang digunakan hanya 1 sensor mq 2 .

\section{Studi Pustaka}

\subsection{Sensor Mq-2}

Sensor MQ-2 adalah sensor yang digunakann untuk mendeteksi konsentrasi gas yang mudah terbakar di udara serta asap dan output membaca sebagai tegangan analog. Sensor gas asap MQ-2 dapat langsung diatur sensitifitasnya dengan memutar trimpotnya.

Sensor ini biasa digunakan untuk mendeteksi kebocoran gas baik di rumah maupun di industri. Gas yang dapat dideteksi diantaranya : LPG, i-butane, propane, methane, alcohol, Hydrogen, smoke.

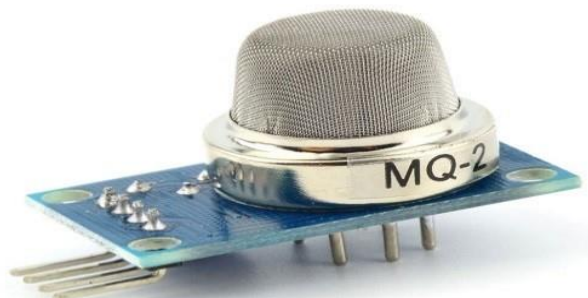

Gambar 1. Sensor MQ 2

Spesifikasi sensor pada sensor gas MQ-2 adalah sebagai berikut:

1. Catu daya rangkaian : $5 \mathrm{VDC}$

2. Range pengukuran : 200 5000ppm untuk LPG, propane 300 - 5000ppm untuk butane 5000 20000ppm untuk methane 300 5000ppm untuk Hidrogen

3. Luaran : analog (perubahan tegangan) 
Sensor ini dapat mendeteksi konsentrasi gas yang mudah terbakar di udara serta asap dan keluarannya berupa tegangan analog. Sensor dapat mengukur konsentrasi gas mudah terbakar dari 300. sampai 10.000 sensor ppm. Dapat beroperasi pada suhu dari $-20^{\circ} \mathrm{C}$ sampai $50^{\circ} \mathrm{C}$ dan mengkonsumsi arus kurang dari $150 \mathrm{~mA}$ pada $5 \mathrm{~V}$.

\subsection{Nodemcu Esp8266}

Node MCU merupakan open source platform IoT, yang di dalamnya sudah terdapat firmware dengan modul wifi ESP 8266 Wi-Fi SoC dari Espressif System, dengan mikrokontroller ESP-12 . Firmware menggunakan bahasa pemrograman Lua. Orang awam sering keliru bahwa Node MCU merupakan Arduino,karena Node MCU dapat menggunakan bahasa pemrograman C Arduino. Secara fungsional memang terlihat sama karena pada dasarnya baik Node MCU maupun Arduino merupakan mikrokontroller development board. Namun penggunaan Node MCU lebih powerfull jika digunakan untuk kontrol berbasis IoT. Gambar 2.2 NodeMcu esp 8266.[5]

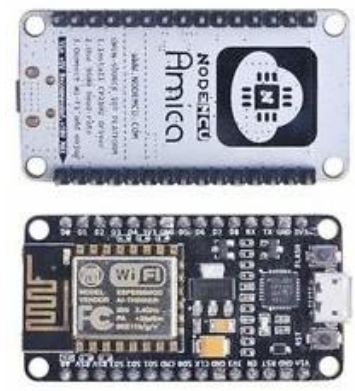

Gambar 2. Nodemcu ESP8266

\subsection{Power Supply}

NodeMcu ESP8266 dapat beroperasi tegangan eksternal 5v. Power Supply adalah suatu alat elektronik yang dapat menyediakan tegangan berupa tegangan DC. Power Supply biasanya digunakan dalam percobaan di laboraturium, project, maupun sebagai pembelajaran dalam bidang elektronika. DC Power Supply befungsi sebagai 'Converter' tegangan dari AC (Alternating Current) ke tegangan DC (Direct Current). Perangkat elektronika membutuhkan tegangan yang lebih kecil serta stabil. Selain disebut catu daya dan adaptor. Power Supply memilki empat bagian utama yakni Transformer, Rectifier, Filter, dan Regulator.

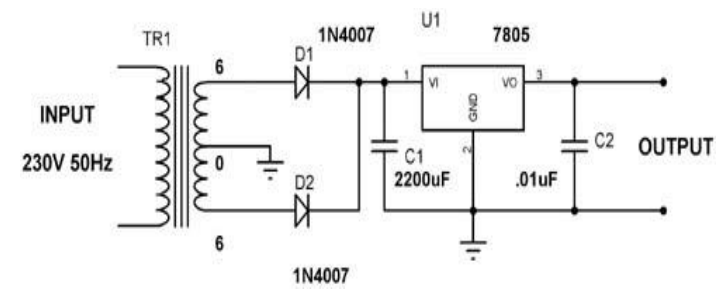

Gambar 3. Skema Power Supply

\subsection{Telegram}

Telegram adalah sebuah aplikasi layanan pengirim pesan instan multiplatform berbasis awan yang bersifat gratis dan nirlaba. Klien Telegram tersedia untuk perangkat telepon seluler (Android, iOS, Windows Phone, Ubuntu Touch) dan sistem perangkat komputer (Windows, OS X, Linux). Para pengguna dapat mengirim pesan dan bertukar foto, video, stiker, audio, dan semua tipe fail atau berkas. Telegram dikembangkan oleh Telegram Messenger LLP dan didukung oleh wirausahawan Rusia Pavel Durov. Kode pihak kliennya berupa perangkat lunak sistem terbuka namun mengandung blob binari, dan kode sumber untuk versi terbaru tidak selalu segera dipublikasikan, sedangkan kode sisi servernya bersumber tertutup dan berpaten. Layanan ini juga menyediakan API kepada pengembang independen[7].

\subsection{Internet Of Things}

Internet of things merupakan sebuah konsep yang bertujuan untuk memperluas manfaat dari konektivitas internet yang tersambung secara terus-menerus. Yang 
memungkinkan daya pengendalian, komunikasi, kerja sama dengan berbagai perangkat keras, berbagi data, memvirtualisasikan segala hal nyata ke dalam bentuk internet, melalui jaringan internet atau disebut juga M2M (machine to machine).[8]

\subsection{Software Arduino Ide}

Aplikasi/software IDE (Integrated Development Environment) Arduino digunakan sebagai media pemrograman Arduino yang terintegrasi. Dengan aplikasi ini dapat menulis program Arduino (disebut juga dengan 'sketch'), mengkompilasi, mendebug jika ada kesalahan pemrograman, dan meng-upload-nya ke papan Arduino. bahasa pemrograman yang digunakan adalah bahasa $\mathrm{C}$ for Arduino, semacam bahasa $\mathrm{C}$ yang dienhance untuk kebutuhan pengaksesan hardware Arduino.

\section{Metode Penelitian}

\subsection{Model Pengembangan}

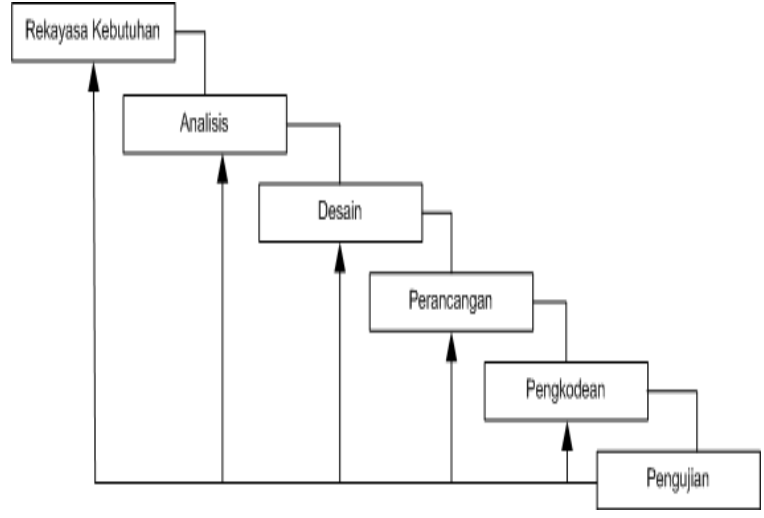

Gambar 4. Model Pengembangan Waterfall

\subsection{Desain}

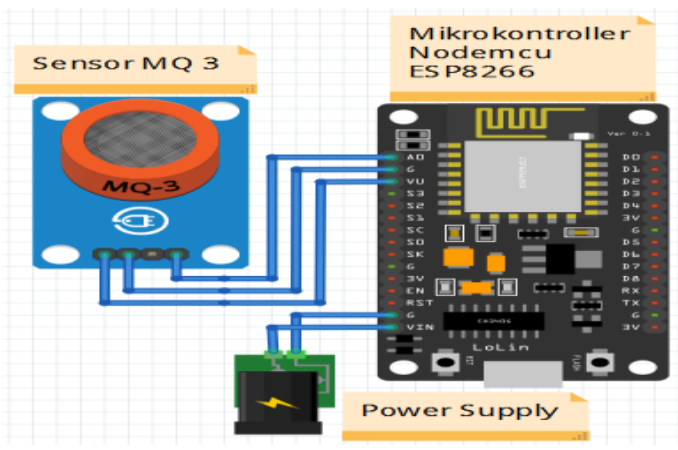

Gambar 5. Desain Sistem Alat Nodemcu Esp 8266 Dengan Sensor Mq 2

a. Perancangan kinerja sistem kontrol

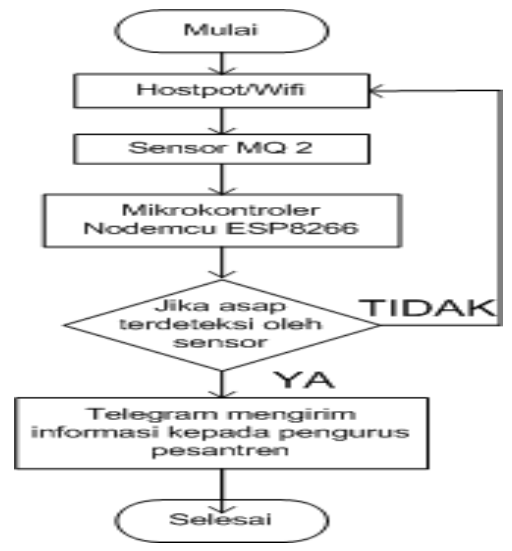

Gambar 6. Flochart Perancangan Sistem

b. Perancangan sistem kontrol

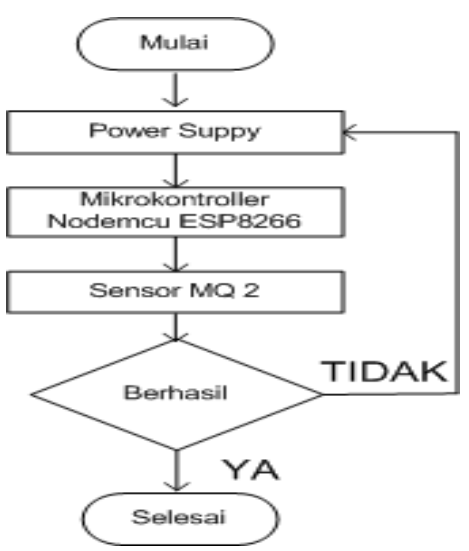

Gambar 6.Flowchart Perancangan Rangkaian Sistem 


\section{Hasil Dan Pembahasan 4.1 Pengujian Internal}

Tabel 1. Pengujian Internal

\begin{tabular}{|c|c|l|l|c|}
\hline No & Unit Uji & \multicolumn{1}{|c|}{$\begin{array}{c}\text { Target ingin } \\
\text { dicapai }\end{array}$} & Hasil yang diharapkan & Keterangan \\
\hline 1 & $\begin{array}{l}\text { Power } \\
\text { supply }\end{array}$ & $\begin{array}{l}\text { Agar bisa } \\
\text { mensupply alat } \\
\text { yang dibutuhkan }\end{array}$ & $\begin{array}{l}\text { Supaya Nodemcu ESP } \\
8266 \text { bisa beroperasi } \\
\text { sesuai harapan }\end{array}$ & Valid \\
\hline 2 & $\begin{array}{c}\text { Nodemcu } \\
\text { ESP8266 } \\
\text { dengan wifi }\end{array}$ & $\begin{array}{l}\text { Terhubung ke } \\
\text { jaringan intemet } \\
\text { mengunakan wifi }\end{array}$ & $\begin{array}{l}\text { Supaya Nodemcu ESP } \\
8266 \quad \text { bisa } \\
\text { berkomunikasi dengan } \\
\text { telegram }\end{array}$ & Valid \\
\hline 3 & $\begin{array}{c}\text { Sensor MQ2 2 } \\
\text { dengan } \\
\text { Nodemcu } \\
\text { ESP8266 }\end{array}$ & $\begin{array}{l}\text { Sensor MQ 2 } \\
\text { mendeteksi asap } \\
\text { rokok dapat } \\
\text { mengirim pesan ke } \\
\text { telegram }\end{array}$ & $\begin{array}{l}\text { Sensor MQ 2 dapat } \\
\text { mengirim pesan ke } \\
\text { telegram }\end{array}$ & Valid \\
\hline
\end{tabular}

\section{Kesimpulan}

1. Pada saat sensor MQ 2 mendeteksi asap rokok maka akan mengirim pesan ke telegram dan jika tidak mendeteksi asap rokok maka tidak akan mengirim pesan ke telegram.

2. Sensor MQ 2 dapat mendeteksi asap rokok dengan jarak maksimal 2 meter.

3. Rangkaian mikrokontroller nodemcu esp8266 dan sensor mq 2 bekerja sesuai rancangan program yang dibuat.

4. Mikrokontroller nodemcu esp8266 harus konek ke wifi agar terhubung ke jaringan internet.

5. Sistem ini dapat mempermudah pengurus pesantren dalam monitoring para santri putra yang melanggar peraturan pesantren yaitu merokok.

\section{Saran}

1. Dengan beberapa pengembangan dan penyempurnaan pada alat ini dapat dikembangkan dengan menggunakan web.

2. Deteksi asap tidak hanya untuk asap rokok, dapat juga mendeteksi asap kebakaran.
3. Diharapkan kedepannya desain alat ini bisa komunikasi dengan whatsapp.

\section{DAFTAR PUSTAKA}

[1]

F. Putri himawan, "PERANCANGAN ALAT PENDETEKSI ASAP BERBASIS MIKROKONTOLLER, MODUL GSM, SENSOR ASAP, DAN SENSOR SUHU," vol. 3, no. 3, pp. 1963-1968, 2017.

P. Mandarani et al., "Perancangan Sistem Deteksi Asap Rokok Menggunakan Layanan Short Message Service ( Sms ) Alert Berbasis Arduino," J. TEKNOIF, vol. 4, no. 2, pp. 66-75, 2016.

[3] D. Akhwandi and A. Yudhana, "SISTEM PENYEGARAN RUANGAN DARI ASAP ROKOK DAN GAS LPG BERBASIS MIKROKONTROLER ATMEGA 8535," vol. 3 , no. 1, pp. 2735, 2017.

[4] T. Hermawan, "MENGENAL SENSOR MQ 2 SEBAGAI SENSOR," 2017. [Online]. Available: http://trianhermawan.blogspot.com/2017/ 10/mengenal-sensor-mq-2-sebagaisensor.html.

[5] R. Purnomo, "Nodemcu ESP8266," 2018. [Online]. Available: http://rizkipurnomo.blogspot.com/2018/0 4/apa-itu-node-mcu.html.

[6] salim, "Power Supply," 2012. [Online]. Available:

https://salinsalim.wordpress.com/tag/ada ptor-dengan-ic-regulator-7805/.

[7] rahayu vivin, "TELEGRAM," 2017. [Online]. Available: https://vivinrahayu24.blogspot.com/2017 /08/membuat-bot-telegram.html .

[8] P. Widya ningtyas, "INTERNET OF THING," 2015. [Online]. Available: https://pritawidyaningtyas.wordpress.co $\mathrm{m} / 2015 / 09 / 15 /$ apa-itu-iot/Internet of Things (IoT)/.

[9] E. Nur, A. Romadhoni, T. Widiyaningtyas, and U. Pujianto, 
"MODEL WATERFALL PADA PENGEMBANGAN SISTEM," no. November, pp. 2-3, 2015.

[10] Saptaji, "Software Arduino Ide," 2015. [Online]. Available: http://saptaji.com/2015/06/28/mengenalbagian-bagian-software-ide-arduino/. 